\title{
Experimental and Numerical Study of a Latent Heat Thermal Energy Storage System Enhanced with Fins
}

\author{
Saeed Tiari ${ }^{1}$, Addison Hockins ${ }^{2}$ Samantha Moretti ${ }^{1,2}$ \\ ${ }^{1}$ Gannon University Biomedical, Industrial, and Systems Engineering Department \\ 109 University Square, Erie, PA, USA \\ ${ }^{2}$ Gannon University Mechanical Engineering Department \\ 109 University Square, Erie, PA, USA \\ tiari001@gannon.edu; hockins001@gannon.edu; moretti001@gannon.edu
}

\section{Extended Abstract}

The lack of a dispatchable energy supply makes transitioning from fossil fuels to green energy alternatives such as solar and wind energy extremely difficult. One solution to remedy this problem is the introduction of a latent heat thermal energy storage (LHTES) unit into an energy system to continue to provide energy long after the original source is gone. LHTES units utilize phase change materials (PCM) as storage media that melt and solidify in the presence of thermal energy. LHTES units using only pure PCMs take a long time to charge and discharge due to PCM low thermal conductivity, making their application in energy systems more difficult. The introduction of thermal conductivity enhancement techniques such as fins, nanoparticles and metallic foam decreases charging and discharging time and increases the thermal efficiency of LHTES units [1-3]. The current study numerically and experimentally analyses a LHTES unit containing Rubitherm RT55 as the PCM and enhanced with fins. Different configurations of metallic fins were examined to maximize the heat transfer to the PCM. These configurations were compared to the operation of the LHTES unit without any enhancement. Both the charging and the discharging cycles of the LHTES unit were studied. The experimental results were compared to numerical simulations completed by ANSYS Fluent 17.0 commercial CFD package. Finding an optimal configuration of a LHTES unit containing PCM and fins allows such units to be integrated with an alternative energy system making the alternative energy more reliable and comparable to their fossil fuel counterpart. The PCM in this study is stored in a cylindrical container which was of $30.48 \mathrm{~cm}$ tall with an inner diameter of $19.05 \mathrm{~cm}$, with a copper pipe that transports the heat transfer fluid at the center of the container. The system is initialized from room temperature $\left(22^{\circ} \mathrm{C}\right)$ and is charged with water at $70{ }^{\circ} \mathrm{C}$. Firstly, the numerical data was compared to the experimental to provide verification for the model. The comparison indicated that the numerical predictions were in good agreement with the experimental data. Two configurations of 10 annular fins and 20 annular fins attached to the central pipe were analysed numerically. These two cases were compared to a benchmark case using no fins. The no-fin case using $70^{\circ} \mathrm{C} \mathrm{HTF}$ took approximately 48 hours to charge. This benchmark was then compared to the finned cases. The 10-fin case took roughly 15 hours to charge, while the 20 -fin case took 12 hours and 40 minutes to fully charge. The resulting percent decreases in charging times were $68.9 \%$ and $73.7 \%$, respectively. When evaluating the discharging cycle of the heat exchanger, it was found that the case utilizing no fins took about 42.5 hours to completely discharge. The 10-fin case took 11 hours and 20 minutes, a 73.2\% decrease in total charging time. The 20-fin case had the fastest discharge cycle, which was 8 hours and 50 minutes, a 79.1\% decrease when compared to the no-fin case. A case can be made that gains in efficiency when using the 20-fin case are offset by the manufacturing cost and difficulty when creating and assembling the fin geometry.

\section{References}

[1] Z. Chen, D. Gao and J. Shi. "Experimental and numerical study on melting of phase change materials in metal foams at pore scale," International Journal of Heat and Mass Transfer, vol. 72, pp. 646-65, Feb. 2014.

[2] Q. Bai, Z. Guo, X. Cui, X. Yang, L. Yanhua, L. Jin, and Y. Sun. "Experimental investigation on the solidification rate of water in open-cell metal foam with copper fins," Energy Procedia, vol. 152, pp. 210-214, Oct. 2018. 
[3] S. Tiari, M. Mahdavi, V. Thakore and S. Joseph. "Thermal Analysis of a High-Temperature Heat Pipe-Assisted Thermal Energy Storage System with Nano-Enhanced Phase Change Material," ASME 2018 International Mechanical Engineering Congress and Exposition, Pittsburgh, PA, Nov. 2018. 